\title{
Improvement of Feeding System in Performance Testing of Japanese Shorthorn Cattle
}

\author{
Yoshitaka Nagamine, Takashi Hayashi, Hiroshi Sato, \\ Akira NisHIDA* and Shigeki Komatsu** \\ Tohoku National Agricultural Experiment Station, \\ Morioka-shi 020-01 \\ * National Institute of Animal Industry, Tsukuba \\ Norin Kenkyu Danchi, Ibaraki-ken, 305 \\ ** Iwate Prefectural Animal Husbandry Experiment \\ Station, Takizawa-Mura, Iwate-ken 020-01
}

(Received January 27, 1988)

Japanese Shorthorn bulls in performance testing were fed concentrate with weight proportional to each body weight and hay ad libitum. However, net energy requirement for maintenance and growth does not increase proportionally to body weight ${ }^{1)}$. The heavier bulls in initial weight on test, therefore, are supplied a larger proportion of required net energy by concentrate than the lighter ones. Ratio of roughage intake (= hay intake $\mathrm{kg} / \mathrm{hay}$ and concentrate intake $\mathrm{kg}$ ) during performance testing of the bulls with heavier initial weight is lower than that of lighter ones. Further, the ratio of roughage intake decreased with increasing body weight in each individual because the proportion of energy from the concentrate increased with increasing body weight. This report presents the results of a new feeding system in performance testing which reduces the effect of initial weight on the other traits and changes the correlations between some traits.

\section{Materials and Methods}

A total of 80 Japanese Shorthorn bulls underwent performance testing for 140 days at the Iwate Prefectural Animal Husbandry Experiment Station from 1982 to 1985. Sixty bulls were fed under the conventional feeding system from 1982 to 1984 . They were given hay ad libitum and concentrate daily, equivalent to $1.4 \%$ of body weight. The other twenty bulls were tested in 1985 with the new feeding system. In this system, hay was given ad libitum but concentrate was supplied equivalent to $6.3 \%$ of the metabolic body size (MB) which was body weight in kilograms raised to the 0.75 power. This new feeding system was implemented by referring to the report from National Research Council (NRC) ${ }^{1)}$ in the USA. The daily allowance of concentrate

日本短角種の直接倹定におりる給聑法の改訂：長嶺慶隆・林 孝・佐藤 博・西田 朗・小松 繁樹（東北農業試験場 盛岡市 020-11） 
Improved Feeding System in Shorthorn Testing

(kg) per head was decided as follows. Net energy requirement for maintenance (NEm) under $10^{\circ} \mathrm{C}$ was

$\mathrm{NEm}(\mathrm{Mcal})$ per day $=0.084 \times \mathrm{MB}$.

The temperature $10^{\circ} \mathrm{C}$ was the annual mean temperature in Morioka ${ }^{2)}$.

If $1.2 \mathrm{~kg}$ of average daily gain (ADG) was expected during the test period, the net energy requirement for growth $(\mathrm{NEg})$ was

$\mathrm{NEg}$ (Mcal) per day $=(1.2)^{1.097} \times 0.0456 \times \mathrm{MB}$.

The upper limit of dry-matter intake (UDM) was assumed to be

UDM $(\mathrm{kg})$ per day $=0.103 \times \mathrm{MB}$.

The value of 0.0456 in equation (2) was closer to the value for large frame bulls than for medium frame bulls in the NRC report ${ }^{1 \text {. }}$. The frame of Japanese Shorthorn was assumed to be similar to a large frame bull ${ }^{3)}$ while the values for large and medium frame bulls were 0.0437 and 0.0493 in the NRC report ${ }^{1)}$, respectively. The value for the Japanese Shorthorn was decided by adding one third of the difference in values between large and medium frame bulls to the value for a large frame bull.

Thus

$$
0.0456=0.0437+(0.0493-0.0437) / 3
$$

The values of 0.084 in equation (1) and 1.097 in equation (2) were constant for all bulls in the NRC report ${ }^{1)}$. The data for dry-matter intake per MB were taken from performance testing records during the period 1982 to 1984 . The value of 1.5 times standard deviation was added to the mean of dry-matter intake per $\mathrm{MB}$, which was $0.103 \mathrm{~kg}$ in equation (3). Since a high ratio of roughage intake is an important characteristic of Japanese Shorthorn, the minimum necessary proportion of concentrate dry-matter $(\mathrm{X})$ and maximum proportion of hay dry-matter $(\mathrm{Y})$ were determined as follows.

$\mathrm{UDM} \geqq \mathrm{NEm} /(2.03 \mathrm{X}+1.27 \mathrm{Y})+\mathrm{NEg} /(1.37 \mathrm{X}+0.70 \mathrm{Y})$

Where $X+Y=1$. The NEm, NEg and UDM were given by equations (1), (2) and (3). In equation (4), 2.03 and 1.27 were the net energy (Mcal) values for maintenance which were contained in $1 \mathrm{~kg}$ of concentrate and hay dry-matter, respectively. The figures of 1.37 and 0.70 were the values of net energy (Mcal) for gain which were contained in $1 \mathrm{~kg}$ of concentrate and hay dry-matter, respectively. The solution to (4) was $\mathrm{X} \geqq 0.53$, which means that at least $53 \%$ of UDM must be supplied from the concentrate. The necessary weight of concentrate dry-matter was given as $0.53 \times$ UDM, but the dry-matter content of concentrate was assumed to be $87 \%$. Therefore, the weight of concentrate supplied to each bull was $0.53 \times$ UDM/ $0.87=0.53$ $\times 0.103 \times \mathrm{MB} / 0.87=0.063 \times \mathrm{MB} \quad(\mathrm{kg} / \mathrm{day})$, where UDM was substituted from the equation (3). For example, if the body weight of a bull was $300 \mathrm{~kg}$ and $1.2 \mathrm{~kg}$ of ADG was expected the daily concentrate allowance was

$$
(300)^{0.75} \times 0.063=4.54 \mathrm{~kg} \text {. }
$$

The NRC report ${ }^{1 /}$ recommended using MB based on shrunk weight which was $96 \%$ of body weight. But the amounts of concentrate based on shrunk and unshrunk body weight differed little. Therefore in the new system, MB based on unshrunk body 
weight was applied because of its simplicity. Body weight was measured once every 2 weeks during the 140 day test period. Therefore, the daily concentrate weight allowance stayed the same for 2 weeks after every weight measurement day. The bulls' back fat thickness was measured ultrasonically ${ }^{4)}$ when their body weight reached $470 \mathrm{~kg}$.

\section{Results and Discussion}

Initial weight averages ( \pm S.D.) of bulls on performance testing were 342 $( \pm 28) \mathrm{kg}$ and $329( \pm 16) \mathrm{kg}$, while ADGs on the test were 1.14 and $1.33 \mathrm{~kg}$ under the conventional and the new feeding system, respectively. There was no significant difference $(p>0.05)$ among coefficients of correlation between initial weight and the ratio of roughage intake in three years and the average of coefficients was -0.37 under the conventional system. The coefficents of correlation between ADG and the ratio of roughage intake in three years were not different $(p>0.05)$ under the conventional system, and the average of the coefficients was 0.09 . MATSUKAwA et al. ${ }^{5)}$ reported that these coefficients under the conventional system were -0.65 and 0.06 , respectively. On the other hand, the correlation between initial weight and the ratio of roughage intake, and the correlation betweem $\mathrm{ADG}$ and the ratio of roughage intake under the new system were -0.10 and 0.50 , respectively. The effect of initial weight on the ratio of roughage intake was reduced and a preferable correlation between ADG and the ratio of roughage intake became higher. The selection on ADG would also improve the performance on utilization of roughage in this new system.

The amount of concentrate supplid to lighter initial weight individuals increased under the new system (Fig. 1). It was feared that this system offered too many advantages to the light initial weight bulls whose pre-test growth rate was low. But the coefficients of correlation between pre-test growth rate (=initial test weight

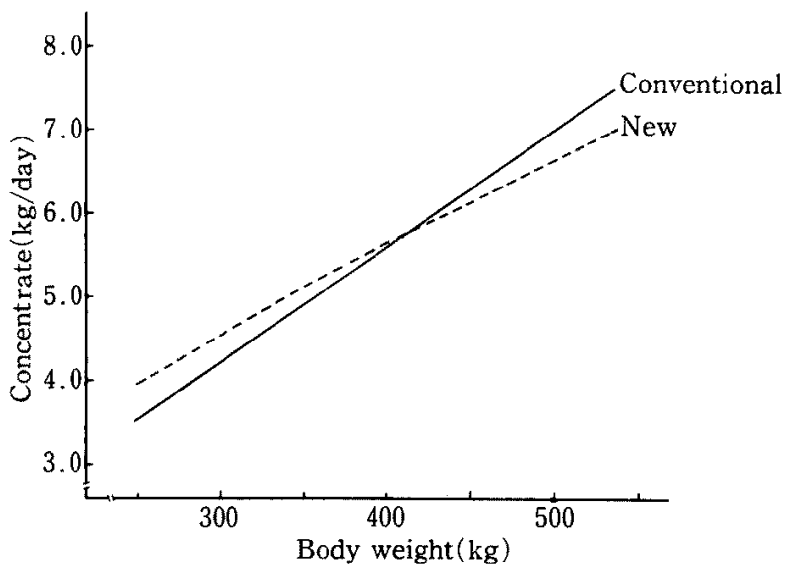

Fig. 1. The change in daily allowance of concentrate for a bull with increasing body weight under the conventional system (solid line) and the new feeding system (broken line). 
$\mathrm{kg}$ /initial test age days) and $\mathrm{ADG}$ on the test under the conventional and the new system were 0.34 and 0.32 , respectively. The coefficients of regression of ADG on pretest growth under the conventional and new feeding system were 0.49 and $0.51 \mathrm{~kg} / \mathrm{kg}$, respectively. There was no significant difference $(p>0.05)$ between the coefficients of regression.

The phenotypic correlation between back fat thickness and ADG was almost 0 and this genetic correlation was positive ${ }^{4)}$ under the conventional system, but phenotypic correlation became -0.21 under the new system. Mikami et al. ${ }^{6)}$ reported that the different feeding system caused the changes in phenotypic and genetic correlations between ADG and back fat thickness in swine. They showed that the phenotypic and genetic correlations were 0.13 and 0.28 under the ad libitum feeding system but that these correlations were -0.16 and -0.02 under the restricted feeding system, respectively. The bulls were fed concentrate more restrictedly in the late stage of the test under the new system than in the conventional one. It was assumed that restricted feeding in the late stage caused negative phenotypic correlation between $\mathrm{ADG}$ and back fat thickness, as in swine. It is necessary to estimate genetic correlation from a larger amount of data under the new system.

The ratio of roughage intake was $41.0 \%$ and $42.1 \%$ under the conventional and the new system, respectively. Body weight was measured biweekly and the ratio of roughage intake was also calculated from data every 2 weeks. The regression of the roughage intake ratio on body weight was calculated for each bull. There was no significant difference $(p>0.05)$ among coefficients of regression over three years under the conventional system. The average of these coefficients was $-0.033 \% / \mathrm{kg}$. The regression coefficient was $-0.034 \% / \mathrm{kg}$ under the new system. The reduction in the ratio of roughage intake with increasing body weight could not be prevented even under the new feeding system.

The values in equations (2), (3) and (4) were reconsidered with data under the new system. The observed ADG of $1.33 \mathrm{~kg}$ under the new system was more than $1.2 \mathrm{~kg}$ in equation (2). The reason for higher observed ADG than expected under the restricted concentrate allowance was due to the good quality of hay. The NEm and NEg content in $1 \mathrm{~kg}$ of hay dry-matter were 1.54 and $0.94 \mathrm{Mcal}$, respectively. These values were higher than expected in equation (4). The correlation between ADG in every 2 weeks and body weight was nearly 0 . Thus $A D G$ was not influenced by increasing body weight. The value of 0.0456 in equation (2) was reexamined from the observed ADG and totally supplied NEg during performance testing. In this case the value of 0.0462 was obtained instead of 0.0456 . This calculation was based on shrunk weight, while 0.0462 was the intermediate value in large and medium frame bulls in the NRC report $^{11}$. Assigned UDM in equation (3) did not differ from the result because the mean ( \pm S.D.) of dry-matter intake per MB was $0.094( \pm 0.006) \mathrm{kg}$. If 1.5 times S.D. was added to the mean, dry-matter intake per MB became $0.103 \mathrm{~kg}$ under the new system.

There were some preferable changes in the relationship between some traits under 
Nagamine, Hayashi, Sato, Nishida and Komatsu

the new system. The effect of initial weight on the ratio of roughage intake was reduced and the correlation between $\mathrm{ADG}$ and the ratio of roughage intake became higher. Also, a negative correlation between ADG and back fat thickness was obtained. Data should be collected in order to estimate precise genetic parameters and construct a selection index under the new feeding system.

\section{Acknowledgements}

The authors acknowledge Mr. K. Koyama and Dr. T. Komryama for their helpful comments.

\section{Refernces}

1) National Research Council, Nutrient Requirements of Beef Cattle. 6th revised ed. 2-61. National Academy Press. Washington D.C. 1984.

2) Japan Meteorological Agency, The Monthly Normals of Temperature and Precipitation. $36: 45.1972$.

3) Koyama, K., Tohoku J. Zootech. Sci., 36 : 209-211. 1986.

4) Nagamine, Y., T. Hayashi, H. Sato, A. Nishida and S. Komatsu, Jpn. J. Zootech. Sci., $59:$ 335-343. 1988.

5) Matsukawa, T., M. Kosugryama and T. Hayashi, Bull. Tohoku Natl. Agric. Exp. Stn., 60 : 105-111. 1979.

6) Mikami, H., H. Tanaka and K. KaI, Jpn. J. Swine Res., 16: 111-117. 1979. 